\title{
a \\ VAMOS ALÉM DO "ERA UMA VEZ": LITERATURA INFANTIL, MATEMÁTICA E QUESTÕES ÉTNICO-RACIAIS NOS ANOS INICIAIS
}

\author{
Let's go beyond "Once upon a time": children's literature, mathematics and ethnic-racial
}

issues in the early years

\author{
Amanda Correia Cidreira \\ Licenciada em Pedagogia \\ Universidade Federal de Mato Grosso do Sul - Mato Grosso do Sul - Brasil \\ amandacorreia.eu@gmail.com \\ http://orcid.org/0000-0001-8854-9986
}

Ana Carolina Faustino

Doutora em Educação Matemática Universidade Federal de Mato Grosso do Sul - Mato Grosso do Sul - Brasil carolina.faustino@ufms.br

\section{Resumo}

http://orcid.org/0000-0002-2059-9466

Este artigo tem como objetivo investigar as potencialidades de conectar matemática, literatura infantil e questões étnico-raciais nos anos iniciais do Ensino Fundamental. Pautada em uma metodologia qualitativa, a produção de dados foi realizada em uma turma do $1^{\circ}$ ano de uma escola pública, em uma cidade do interior de Mato Grosso do Sul (MS). Os dados foram registrados por meio de vídeos, fotos e anotações no diário de campo. Na pesquisa, foi analisada uma sequência didática desenvolvida durante três dias, que trabalhou conteúdos relacionados a grandezas e medidas a partir do livro: "As panquecas de Mama Panya", de Mary e Rich Chamberlin. Os resultados indicam que os estudantes se tornaram mais participativos quando o conceito matemático é introduzido por uma história de literatura infantil, possibilitando que números inteiros e fracionários fossem trabalhados a partir de um contexto significativo em que cada um deles tinha um referente na receita do livro. A presença de personagens negros na história, inclusive como protagonista, em um contexto positivo contribui para a construção de uma identidade cultural positiva, para o reconhecimento e a valorização da diversidade cultural.

Palavras-chave: Literatura Infantil. Anos Iniciais. Educação Matemática. Diversidade. Relações étnico-raciais.

\begin{abstract}
This article aims to understand the potential of working with mathematics connected to children's literature and ethnic-racial issues in the early years of elementary school. Based on a qualitative methodology, the production of data was carried out in a class of the first year of a public school, in a city of the Mato Grosso do Sul (MS). The data were recorded through videos, photos and notes in the researcher's field diary. In the research, a didactic sequence developed over three days was analyzed, which worked on contents related to quantities and measurements from the book: "Mama Panya's Pancakes", by Mary and Rich Chamberlin. The results indicate that students became more participatory when the mathematical concept is introduced through a history of children's literature, allowing integer and fractional numbers to be taught from a significant context in which each one had a referent in the
\end{abstract}


recipe of the book. The presence of black characters in history, including as a protagonist, in a positive context contributes to the construction of a positive cultural identity, to the recognition and appreciation of cultural diversity.

Keywords: Children's literature. Elementary School. Mathematics Education. Diversity. Ethnic-racial relations

\section{Introdução}

O interesse para desenvolver esta pesquisa, bem como o delineamento do objeto de estudo, se deu a partir das vivências familiares da primeira autora que, desde a infância, teve contato com a história de seus ancestrais, apresentada por seu pai que pratica capoeira, uma luta afro-brasileira que aborda muitos aspectos da história da África e de seus descendentes. Tais aspectos contribuíram para que ela desenvolvesse uma identidade cultural positiva e se reconhecesse como mulher preta, que valoriza a importância da representatividade, e de uma educação antirracista desde o início da escolarização.

Soma-se a estes aspectos a participação dela nas disciplinas Fundamentos e Metodologias da Matemática I, Fundamentos e Metodologias da Matemática II, e sua participação no Programa Institucional de Bolsas de Iniciação à Docência (Pibid) no subprojeto do curso de Licenciatura em Pedagogia da Universidade Federal de Mato Grosso do Sul, campus de Naviraí (UFMS/CPNV), coordenado pela segunda autora, e que tinha como foco a alfabetização matemática das crianças. Nos encontros do Pibid, foram discutidos referenciais teóricos que abordavam as potencialidades da literatura infantil no processo de ensino e aprendizagem da matemática; os licenciandos elaboraram e desenvolveram atividades que se pautavam nesta conexão tanto na Educação Infantil quanto nos anos iniciais do Ensino Fundamental.

Outro espaço formativo que contribuiu para essa opção foi o TA'ARÕMBY ${ }^{1}$ - Grupo de Estudo e Pesquisa em Educação Matemática e Sociedade da UFMS/CPNV, coordenado pela segunda autora. Nos encontros do grupo, são discutidos, por exemplo, referenciais teóricos referentes à Educação Matemática Crítica e Educação Matemática para Justiça Social. Um dos objetivos desta é a construção de uma identidade cultural positiva que engloba a contribuição das diferentes culturas para o conhecimento matemático, assim como a possibilidade de todos os estudantes compreenderem que aprender matemática pode estar conectado com seu background (GUTSTEIN, 2006).

${ }^{1}$ TA'ARÕMBY: Traduzido do idioma Guarani, significa "Esperança" segundo o dicionário Avañe'ẽ - Lino (2008). 
Freire (2014) tem destacado que a educação é um ato político. Assim, a escolha de um livro para ler na sala de aula que, a princípio, pode supor-se neutra, não é. Os livros podem trazer um ideal de beleza, por exemplo, ligado a características de fenótipos branco e magro, como ainda marcas culturais europeias. Assim, um conjunto de questões essenciais emergiu: o que é literatura infantil? Que livro de literatura infantil levar para a sala de aula? Quais potencialidades ele tem para fazer os estudantes apreciarem o livro? Como são as personagens desse livro? Em que lugar ele se passa? Este livro contribuirá para que a criança viaje para outros lugares? Ele traz consigo a diversidade e a riqueza de diferentes culturas? Ele contribui para a construção de uma identidade cultural positiva? Ele contribui para que a matemática seja trabalhada de forma interdisciplinar e potencializa o desencadeamento de situações-problemas? Pensando nestas, foi elaborada e desenvolvida uma sequência didática em que foram abordados conteúdos relacionados a grandezas e medidas a partir do livro de literatura infantil "As panquecas de Mama Panya", de Mary e Rich Chamberlin.

A definição de literatura infantil, defendida neste texto, vai ao encontro do entendimento de Souza e Carneiro (2015, p. 2), em relação à literatura infantil:

[...] a literatura infantil engloba os livros e os textos ditos "clássicos" da literatura, como as histórias dos irmãos Grimm e os contos de Andersen, entre outros; os textos contemporâneos, também denominados "contos realistas" e direcionados ao público infantil; e os livros paradidáticos.

Souza e Carneiro (2015) ainda apontam que livros paradidáticos são desenvolvidos para ensinar conteúdos didáticos utilizando histórias da literatura de forma lúdica, com personagens ilustrativos utilizando contextos reais e hipotéticos, possibilitando o diálogo por meio dos elementos textuais como cenário, personagens e conflitos da história.

Montoito (2019) enfatiza a importância de colocar óculos matemáticos ao ler uma história, para que, assim, possa analisar o que ela pode representar em diferentes aspectos, que não sejam apenas literários, e atentar-se às potencialidades que a história abrange, e não apenas na trama que ela relata. Este é o primeiro passo para começar a ver a literatura em outros aspectos, pois um conto de literatura pode trazer diversas possibilidades de ensino. O autor também destaca que todas as disciplinas têm um compromisso com a alfabetização dos estudantes, inclusive a de matemática. A leitura deve ser incentivada por todos os professores, independente da matéria que ministram, o que é crucial para o desenvolvimento de um bom leitor. Tal perspectiva é produtiva não só para os estudantes, mas também para o professor que pode desenvolver a criatividade, explorar suas potencialidades imaginárias e simbólicas, afirmação essa que vai ao encontro de Munanga (2005), que ressalta que um professor ou um 
educador numa classe é como um ator único em um cenário único.

Sendo assim, a literatura pode ser abordada como forma de integração para que os estudantes passem a compreendê-la como parte de seu cotidiano, e que as histórias possam contribuir para o ensino e a aprendizagem da matemática possuindo termos e conceitos que possibilitam criar um vínculo maior ao desmistificar o medo em relação à disciplina. Montoito (2019) também ressalta que a literatura pode ser inovadora e lúdica, possibilitando que as crianças reflitam sobre algumas noções de matemática em seu cotidiano, conheçam novas realidades e ainda serve como um complemento para o material utilizado nas aulas.

Souza e Carneiro (2015) ressaltam que a conexão entre literatura e matemática permite ao estudante refletir e discutir realidades diferentes da sua, apreciar novas possibilidades, culturas e diálogos podendo também conectar o conhecimento matemático com a sua vivência cotidiana com base nas diferentes visões de mundo presentes na literatura. Os autores ainda enfatizam a importância de imagens, personagens e paisagem, possibilitando que o leitor aflore sua imaginação e, quando relacionadas à matemática, as ilustrações podem contribuir para a compreensão de conceitos matemáticos.

Lannes (2019) analisou, em sua dissertação de mestrado, obras atuais da literatura infantil que podem contribuir para o empoderamento de crianças negras ao abordarem, por exemplo, a representatividade dos cabelos crespos. Entre as obras analisadas estão "As tranças de Bintou", de Sylviane A. Diouf; "Menina Bonita do Laço de Fita", de Ana Maria Machado; "Os cabelos de Sara", de Gisele Gama Andrade; "Os mil cabelos de Ritinha", de Paloma Monteiro"; "Meninas negras", de Madu Costa; "Meu crespo é de rainha", de Bell Hooks; "O cabelo de Cora", de Ana Zarco Câmara, entre outras. Segundo a autora, livros como "As Tranças de Bintou" destacam características de beleza que se distanciam de uma perspectiva eurocêntrica e abrem espaço para a valorização de outras belezas que são apresentadas de forma positiva no contexto da história. A autora destaca que uma das possíveis formas de se combater o racismo se dá por meio da representatividade que o negro tem em diferentes esferas do meio social incluindo a literatura infantil, contribuindo para a construção de uma identidade positiva do negro, seus ancestrais e da cultura afrodescendente, propiciando conhecer elementos da cultura africana.

Há uma expressiva quantidade de pesquisas que abordam a literatura infantil e a matemática, contudo pouco se tem discutido sobre as questões étnico-raciais presentes em histórias de literatura infantil nas aulas dessa disciplina. Como disposto na Lei $\mathrm{n}^{\mathrm{o}} 10.639$ de 9 de janeiro de 2003 (BRASIL, 2003), no artigo 26-A, parágrafo $2^{\circ}$ : "Os conteúdos referentes à História e Cultura Afro-Brasileira serão ministrados no âmbito de todo o currículo escolar, em 
especial nas áreas de Educação Artística e de Literatura e História Brasileiras". Desta forma, é importante que sejam abordados conteúdos relacionados às questões étnico-raciais em todas as áreas do conhecimento, inclusive nas aulas de matemática. A Lei $n^{\circ}$ 10.639/03 é um marco na educação brasileira como ruptura de uma preeminência da cultura europeia. Coelho e Constantino (2020), afirmam que aplicar a lei no contexto escolar significa acabar com o silêncio da escola sobre negritude, cultura e identidade e pensar ações que considerem a diversidade da nossa sociedade.

É preciso considerar que o ensino e a aprendizagem da matemática podem abranger a diversidade cultural, as contribuições dos diversos grupos étnicos para a formação da cultura brasileira, a diversidade e a riqueza do continente africano, contribuindo para o combate ao racismo. Isto posto, este artigo tem como objetivo investigar as potencialidades de conectar matemática, literatura infantil e questões étnico-raciais nos anos iniciais do Ensino Fundamental.

Este trabalho é composto desta introdução e de mais quatro seções. Na primeira delas, é apresentada uma revisão bibliográfica que foi realizada por meio da busca por relatos de pesquisa e relatos de experiência nos anais de três edições do evento Encontro Nacional de Educação Matemática (Enem). Na segunda, são apresentados os procedimentos metodológicos utilizados. Na terceira, revelam-se os episódios referentes à sequência didática que foram desenvolvidos com os estudantes na escola, que abordavam os conceitos de grandezas e de medidas, entre outros, por meio da história: "As panquecas de Mama Panya". Por fim, são apresentadas as considerações finais.

\section{Literatura Infantil e Matemática nos anais do "Enem"}

O presente trabalho tem, como objetivo, investigar as potencialidades de conectar matemática, literatura infantil e questões étnico-raciais nos anos iniciais do Ensino Fundamental. Dessa forma, buscou-se aprofundar sobre os estudos relacionados à literatura infantil e à matemática e foi realizado um mapeamento bibliográfico nos anais do Encontro Nacional de Educação Matemática (Enem), nas edições de 2013, 2016 e 2019. Para buscar estes trabalhos nos anais dos eventos, foram utilizadas como palavras-chave: "literatura" e "literatura infantil"; em seguida, foram lidos os resumos e os textos que abordavam tal temática nos anos iniciais, relacionados à matemática, os quais serão descritos neste trabalho conforme Tabela 1 e 2, a seguir. 
Tabela 1 - Pesquisas encontradas nos anais das edições XI, XII e XIII do ENEM

\begin{tabular}{lcc}
\hline \hline Modalidade de ensino & $\begin{array}{c}\text { Quantidade de } \\
\text { trabalhos }\end{array}$ & Total de trabalhos \\
\hline $\begin{array}{l}\text { Anos iniciais do Ensino } \\
\text { Fundamental. }\end{array}$ & 8 & 19 \\
\hline \hline $\begin{array}{l}\text { Anos finais do Ensino } \\
\text { Fundamental e Ensino } \\
\text { Médio. }\end{array}$ & 6 & \\
\hline \hline $\begin{array}{l}\text { Educação de Jovens e } \\
\text { Adultos (EJA). }\end{array}$ & 2 & \\
\hline Formação de professores e \\
Ensino Superior.
\end{tabular}

Fonte: As autoras (2020).

Tabela 2 - Pesquisas que abordam a literatura infantil nos anos iniciais

\begin{tabular}{cccc}
\hline \hline XI ENEM (2013) & XII ENEM (2016) & XIII ENEM (2019) & Total \\
\hline \hline 00 & 1 & 8 & 9 \\
\hline \hline \multicolumn{4}{c}{ Fonte: As autoras (2020). }
\end{tabular}

No mapeamento dos trabalhos no XI Enem que ocorreu em Curitiba (PR), em 2013, com a temática: "Retrospectivas e perspectivas da Educação Matemática no Brasil", foram identificados dois trabalhos com a temática pesquisada, ambos realizados nos anos finais do Ensino Fundamental, razão pela qual estes não entram no escopo de análise.

Na edição do XII Enem, realizado em São Paulo (SP), no ano de 2016, com a temática "A Educação Matemática na Contemporaneidade: desafios e possibilidades", foram identificados 4 trabalhos, sendo que um deles direcionado a estudantes surdos na Educação de Jovens e Adultos (EJA); dois relacionados aos anos finais do Ensino Fundamental; e um direcionado à formação de professores nos anos iniciais, sendo este o único trabalho que será descrito, pois abrange a faixa etária pesquisada.

Souza e Côco (2016) abordam dados parciais da sua pesquisa de mestrado, realizada em um grupo de extensão composto por professores dos anos iniciais e pesquisadores que se reúnem semanalmente para discutir e analisar possibilidades de ensinar grandezas e medidas utilizando a literatura infantil. Neste grupo, todas as semanas são levados livros de literatura infantil e os professores dão sugestões e recebem orientações de como tornar possível este vínculo entre a matemática e a literatura infantil. No encontro descrito pelas autoras, foi selecionado o livro "Pedro e a Lua", em que o personagem principal chamado Pedro quer dar a lua de presente à sua mãe e, como ela está no céu, ele cria estratégias para alcançá-la. Após a leitura, as autoras apontam que os professores discutiram sobre as possíveis formas que o livro pode abordar a matemática, chegando, assim, ao bloco de conteúdo de grandezas e medidas. Os 
resultados deste estudo evidenciam a importância de se explorar os conhecimentos contidos em uma história literária, e a forma que a literatura de qualidade favorece a capacidade da imaginação de procurar soluções de forma que prende a atenção tanto do professor que está participando do grupo quanto do estudante ao ser abordado em sala de aula.

Por fim, nos anais do XIII Enem que ocorreu no município de Cuiabá (MT), no ano de 2019, com a temática: "Educação Matemática com as Escolas da Educação Básica: interfaces entre pesquisas e salas de aula", foram identificados catorze trabalhos que abordavam literatura, porém, apenas oito nos anos iniciais do Ensino Fundamental.

O trabalho de Pinheiro e Bezerra (2019) se constitui em um artigo teórico que apresenta as contribuições da literatura infantil e da contação de história no ensino e aprendizagem da matemática nos anos iniciais. As autoras enfatizam que a literatura pode ser facilitadora nesse processo. Fundamentando-se na alfabetização matemática na perspectiva do letramento, destacam a importância de se utilizar histórias literárias no processo de aprendizagem. Outro ponto destacado pelas autoras são as ilustrações geralmente pertencentes aos livros de literatura infantil, que podem desenvolver a imaginação do estudante e o prazer por aprender tornando-o mais participativo, pois, para ele, o conteúdo tem significado; assim, pode compreender os conceitos de linguagem matemática, já que, através da literatura, esta linguagem é contextualizada, o que passa a dar sentido ao que está sendo aprendido.

Weissheimer, Cunha e Montoito (2019) apresentam parte de sua pesquisa de Mestrado Profissional em Educação e Tecnologia do Instituto Federal de Educação, Ciência e Tecnologia Sul-rio-grandense. A partir do livro de literatura infantil "As aventuras (topológicas) do avião vermelho", os autores apresentam algumas sequências didáticas como sugestões aos professores dos anos iniciais, as quais possibilitam trabalhar com os estudantes noção de vizinhança, de espaço, entre outros, visando à ressignificação do livro de Veríssimo do ponto de vista matemático-geométrico.

Santos e Ciríaco (2019) analisam livros disponíveis no acervo paradidático do programa Pacto Nacional pela Alfabetização na Idade Certa (Pnaic) para crianças no período de alfabetização de primeiro a terceiro ano do Ensino Fundamental e, em seu trabalho, propõem ao professor trabalhar a matemática por meio de histórias de literatura infantil. O primeiro livro selecionado foi "Aperte aqui", e a primeira atividade proposta pelos autores se trata de uma exposição de bolinhas posicionadas uma atrás da outra e que seguem um padrão de cores, possibilitando o desenvolvimento do pensamento algébrico através daquela imagem que representa sequência e padrão. 
O segundo livro apresentado foi "E o dente ainda doía", que aborda a numeração e a posição hierárquica dos números ao ir aumentando animais, um a um, cada vez que passa para a página seguinte. A atividade proposta é levar um papel manilha e animais de papel e, conforme o livro for acrescentando um animal, a professora vai montando um gráfico, para que, mesmo aqueles que não compreendem o valor do algarismo representado no livro, percebam que está aumentando através do gráfico.

O terceiro e último livro, "Gabriel tem 99 centímetros", aborda conceitos de grandezas e medidas. Os autores destacam a necessidade de iniciar este conteúdo com instrumentos de medidas não convencionais como, por exemplo, o barbante, palmos ou pés para que as crianças percebam a necessidade de um instrumento de medida padrão. Para que os estudantes desenvolvam esta percepção, os autores sugerem que o professor proponha uma atividade na qual tenham que medir uns aos outros com barbante e canudos e pedir que analisem qual medida economiza mais tempo, por exemplo, e propõem perguntas que os levem à reflexão. Os resultados do estudo evidenciam a importância dos livros paradidáticos disponíveis na escola e sua utilização na alfabetização matemática.

Lopes e Filho (2019) relatam a experiência de uma professora alfabetizadora, em uma turma de $2^{\circ}$ ano, que tem como objetivo descrever algumas práticas alfabetizadoras que utilizam a literatura infantil nas aulas de matemática e envolvem operações de adição, subtração e outras relacionadas ao eixo de números e operações. A primeira atividade descrita pelos autores era a resolução de problemas e, para isso, a professora utilizou o livro "Apostando com o monstro". No decorrer da história, surgem alguns problemas matemáticos: "Quantas melancias o monstro comeu a mais que o velhinho?", trabalhando, assim, as operações matemáticas de adição e de subtração e sua relação com os termos: a mais ou a menos. No decorrer da atividade, a professora também trabalhou com os estudantes a importância da amizade e de contextos sociais, associando à história. Os autores ressaltam que as operações matemáticas, por muito tempo, foram ensinadas como memorização de fórmulas e tabuada. Já o uso da literatura para alfabetização matemática possibilita que esta realidade mude e que os estudantes compreendam a operação.

Adam e Jelineck (2019) trazem, em seu texto, possibilidades para se trabalhar o pensamento algébrico através da literatura infantil. Para tanto, desenvolveram sequências didáticas com uma turma do primeiro ano com o objetivo de trabalhar a capacidade de identificar sequências e padrões. O primeiro texto escolhido para exemplificar esta prática se chama "Quem vai ficar com o pêssego?". Após a leitura do livro, os estudantes confeccionaram palitoches para cada um dos personagens e recontaram a história tentando lembrar a sequência. 
Em seguida, a professora entregou outra folha com animais, sendo que alguns deles estavam presentes na história e outros, não. Os estudantes recortaram as figuras e as colocaram no quadro seguindo a ordem da história e os animais que não faziam parte desta foram descartados. Desta forma, ela pode trabalhar com eles noções de sequência e de padrão, características do pensamento algébrico.

A pesquisa de Silva, Andrade e Guimarães (2019) tinha como objetivo investigar se professores dos anos iniciais desenvolvem processos de ensino e aprendizagem de conceitos estatísticos a partir de situações interdisciplinares envolvendo literatura infantil e como os conduzem. As autoras entrevistaram vinte professores da rede pública da cidade de Jaboatão dos Guararapes (PE) para constatar quantos deles utilizavam a literatura infantil no processo de ensino de estatística.

Constatou-se que apenas quatro desses professores utilizavam a literatura como auxílio pedagógico para ensinar a matemática; eles relatam que as escolas possuem acervo de literatura infantil, porém os utilizam apenas como leitura deleite. As autoras relatam algumas atividades que as professoras realizaram com os estudantes no decorrer da pesquisa. Na primeira, utilizaram o livro "Clact...Clact...Clact", de Liliana e Michele Lacocca para trabalhar estatística. O texto foi lido pelas professoras juntamente com os estudantes com o auxílio de um projetor e, em seguida, elas passaram atividades para que os estudantes classificassem as figuras; por exemplo: mulher com mulher, homens com homens. Já no $5^{\circ}$ ano, a professora propôs que os estudantes, em conjunto, realizassem esta divisão através de critérios criados por eles mesmos. O segundo livro utilizado pelas professoras se chama "Fugindo das garras do gato", de Choi Yun-Jeong e Kim Sun-Yeong. No decorrer da leitura, os estudantes foram interagindo e expondo suas opiniões para resolver os problemas que surgiam no decorrer da história; também montaram um gráfico na lousa para se posicionarem como personagens da história. Nessa atividade, puderam analisar o quanto os estudantes foram participativos e críticos na resolução dos problemas.

No site da Sociedade Brasileira de Educação Matemática (Sbem), Reis, Júlio e Eufrásio (2019) realizaram uma busca por trabalhos científicos relacionados ao tema literatura $e$ literatura infantil. Por meio desta base, buscaram analisar as possibilidades de trabalhar a literatura infantil junto com a matemática. As autoras destacam a importância do compartilhamento de ideias entre professores de matemática e de língua portuguesa para uma elaboração de aula na qual uma liga à outra, tendo, assim, mais significado e melhor compreensão por parte dos estudantes. As autoras identificaram quinze trabalhos, sendo três deles de acesso restrito, e os resultados encontrados proporcionaram compreender que, através 
da aprendizagem utilizando a literatura infantil e a matemática, os estudantes desenvolveram a capacidade de lidar com diferentes linguagens como a literária, matemática, cotidiana, dentre outras, para a produção de conhecimentos e posicionamentos perante o mundo e também permite que eles passem a expressar opiniões, a classificar, ordenar, levantar hipóteses, formular e resolver problemas.

Castro, Neres, Nascimento e Souza (2019) abordam, em seu trabalho científico, o relato da prática de quinze professores do Ensino Fundamental da rede pública de Raposa/MA, com o intuito de destacar as obras usadas em conjunto com a literatura infantil para a construção de conceitos matemáticos em sala de aula, a partir de dados produzidos em um curso de formação continuada em ambiente virtual, disponibilizado pelo município e que poderiam colaborar para o desenvolvimento das aulas destes professores. O primeiro livro utilizado foi "Poemas problemas", de Renato Bueno, que possui problemas os quais, no decorrer da história, vão sendo resolvidos pelos estudantes, trabalhando, assim, sequência numérica e as quatro operações básicas da matemática; este livro foi abordado por oito professores em sala de aula.

O segundo livro utilizado foi "Os Problemas da Família Gorgonzola", de Eva Furnari, que aborda conceitos de resolução de problemas, sistema monetário e as operações matemáticas. Os professores destacam que é muito interessante abordar estes conteúdos matemáticos por meio da história pois, desta forma, os alunos veem estes conteúdos como parte do seu cotidiano. Este livro foi utilizado por quatro professoras em sala de aula. O terceiro livro abordado foi "A surpresa de Handa", de Eileen Browne, que retrata a história de uma menina que leva uma cesta de frutas a uma colega; no entanto, no decorrer do caminho, os frutos vão sendo retirados da cesta por animais da savana africana. Com este livro, as professoras puderam trabalhar o conceito de adição e subtração de forma lúdica e bem ilustrada, possibilitando a compreensão dos estudantes. Esta história foi abordada por duas professoras em suas classes. Destacamos que, no texto dos autores, a justificativa para a escolha deste livro se restringe aos conceitos matemáticos. As potencialidades para abordar questões étnico-raciais não foram mencionadas no texto.

Os resultados do mapeamento realizado nos anais do ENEM, dos anos de 2013, 2016, 2019, abrangem uma quantidade de trabalhos que vêm se desenvolvendo de forma crescente com o propósito de conectar literatura infantil e matemática. Esses ressaltam que a literatura infantil, quando utilizada como facilitadora para o ensino da matemática, pode possibilitar a familiarização e reconhecimento dos estudantes com o conteúdo, pois as histórias possuem uma ligação direta com a língua materna. Além disso, os livros de literatura infantil possuem aspectos não verbais (figuras) que estimulam a imaginação do estudante e o prazer por aprender. 
Quando estes estão aliados ao texto, criam um contexto para os termos matemáticos contribuindo para que as crianças os compreendam. Os trabalhos ainda trazem uma gama de sequências didáticas pautadas em livros da literatura infantil; entre eles, obras presentes no Pnaic, bem como apresentam práticas pedagógicas de professores da rede de ensino de alguns estados do Brasil que também conectam literatura infantil e matemática. Pode-se, ainda, notar que os trabalhos abordam a literatura infantil e a matemática sem destacar as potencialidades de trabalhar a diversidade como as questões étnico-raciais.

\section{Metodologia}

A pesquisa busca compreender as potencialidades de conectar matemática, literatura infantil e questões étnico-raciais nos anos iniciais; sendo assim, optou-se por realizar uma pesquisa qualitativa descritiva. De acordo com Gil (2008, p. 28), "as pesquisas deste tipo têm como objetivo primordial a descrição das características de determinada população ou fenômeno ou o estabelecimento de relações entre variáveis". Pesquisadores que adotam a pesquisa qualitativa não se prendem à ideia que defende um modelo único de pesquisa para todas as ciências. Estes pesquisadores se recusam a expor seus conhecimentos por processos quantificáveis que venham a se transformar em leis e explicações gerais. Afirmam que a pesquisa qualitativa tem sua especificidade, que abrange uma metodologia própria (GOLDENBERG, 2004).

Assim, priorizando atingir o objetivo deste estudo, a produção de dados foi realizada em uma turma do primeiro ano do Ensino Fundamental de uma escola pública estadual em uma cidade no interior de Mato Grosso do Sul (MS). Esta era composta por 31 estudantes e a professora, a qual era supervisora do subprojeto do curso de Licenciatura em Pedagogia da UFMS/CPNV, na qual a primeira autora desenvolvia as atividades do Pibid.

O desenvolvimento das atividades foi realizado em três dias, especificamente nas terçasfeiras. O desenvolvimento de tais práticas foi precedido pelas reuniões do subprojeto que aconteciam na UFMS/CPNV, buscando aprofundar os conhecimentos teóricos sobre alfabetização matemática, bem como desenvolver sequências didáticas pautadas em tais discussões. Os dados foram registrados por meio de vídeos, fotos e anotações no diário de campo, sendo estes posteriormente analisados pelas autoras. As gravações em vídeo foram vistas diversas vezes possibilitando a imersão nos dados e foram feitas anotações que contribuíram para a descrição do contexto. Além disso, foram identificados eventos que contribuíram para a compreensão do objeto de pesquisa e para a confirmação ou refutação de 
hipóteses. Dentre estes eventos estão trechos das falas dos estudantes que foram transcritos. Em seguida, foram elaborados os episódios.

Neste artigo, aborda-se uma sequência didática para trabalhar a matemática contígua com a literatura infantil e questões étnico-raciais, a qual é descrita em três episódios e, posteriormente, analisada a partir de suas contribuições para o ensino e a aprendizagem dos conceitos matemáticos e para a valorização da diversidade e combate ao racismo.

\section{Uma história no Quênia: possibilidades nas aulas de matemática}

No início da aula, ficou combinado que os estudantes podiam participar e perguntar levantando a mão para que todos escutassem os seus argumentos ou suas perguntas. Em seguida, com a utilização do projetor, iniciou-se uma viagem a partir da história: "As panquecas de Mama Panya", de Mary e Rich Chamberlin (Figura 1). É a história de Mama Panya e um garoto chamado Adika que percorriam um caminho até a feira para comprar ingredientes para o preparo de panquecas; no percurso, o garoto se encontra com vários amigos convidando todos para comerem as panquecas em sua casa. Por fim, o livro também aborda diversos aspectos do Quênia e do continente africano.

Figura 1: Capa do livro

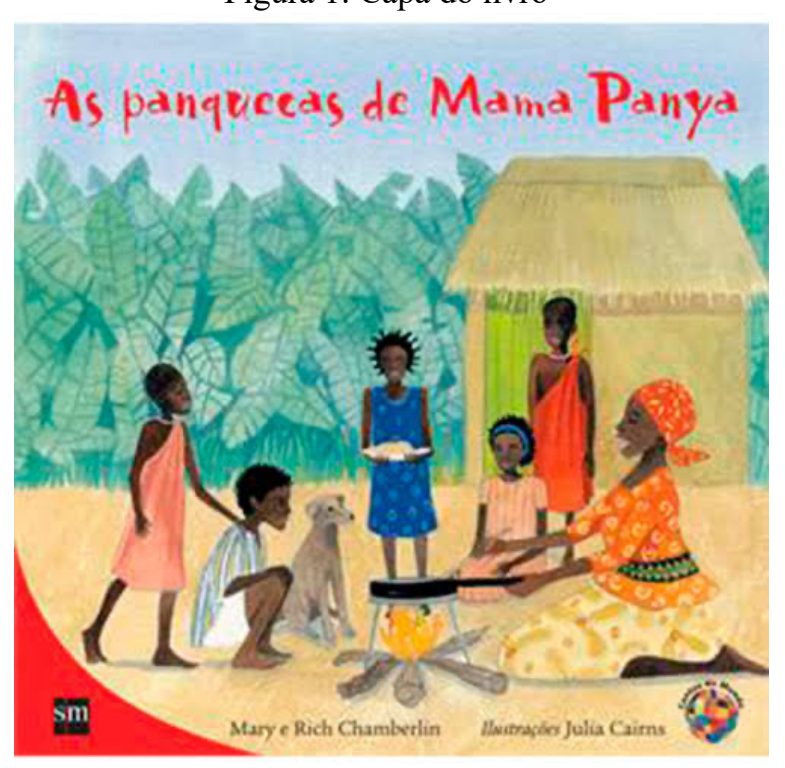

Fonte: google imagem

O silêncio tomou conta da sala de aula, os estudantes estavam encantados e atentos. Ao finalizar a história, iniciou-se uma conversa sobre o que haviam notado de diferente na história daquele país. Alguns observaram as roupas de Adika e Mama Panya e um estudante argumentou 
de forma espontânea e curiosa: "Nossa, como se vestem bem, as roupas são tão lindas e coloridas!". Outros comentaram sobre o mercado que era diferente do que eles estavam acostumados, destacaram as características dos animais, das árvores e da escola. Nas páginas finais do livro, são trazidas informações sobre a escola, a aldeia, os animais etc. Uma se refere à longa distância entre a escola e as casas; então, iniciou-se uma discussão sobre o percurso que as crianças percorriam de suas casas até a escola, descrevendo-o como longo ou curto.

Alguns estudantes disseram que moravam muito perto, outros enfatizaram que era longe. Para que eles compreendessem melhor o trajeto que percorriam, fizeram um desenho do caminho. Enquanto realizavam a ilustração do trajeto, um estudante perguntou: "Professora, preciso desenhar as curvas que faço quando viro em uma rua?". Aproveitando o momento, outro esboçou outra dúvida: "Eu preciso desenhar as casas que vejo até chegar na minha casa?". Foi oportunidade para responder para toda a classe que podiam desenhar da forma que achassem melhor e trazer detalhes como casas, mercados e curvas que faziam quando viravam para outra rua. Notando as dúvidas dos estudantes, foi oportuno passar de mesa em mesa tirando dúvidas e discutindo ideias de pontos que passavam, entre outros detalhes que surgiam no decorrer da elaboração dos desenhos. Em seguida, abriu-se um diálogo sobre a importância da utilização de termos como direita, esquerda, ponto de partida e ficou estabelecido coletivamente que o ponto de partida seria o portão da escola.

Depois de finalizado o desenho, cada estudante compartilhou com o restante da turma o seu percurso, explicando-o oralmente. O primeiro estudante teve um pouco de dificuldade. Então, foi observado que eles poderiam andar na sala mostrando como era o percurso. Os próximos estudantes pegaram o jeito, alguns levantaram e andaram nas direções pela sala enquanto descreviam o caminho. Outros explicaram oralmente sua localização espacial sem se levantarem.

Posteriormente, leu-se a receita que a Mama Panya utilizava na história e também foi trabalhado um texto que abordava curiosidades sobre a origem das panquecas e suas modificações em diferentes países. Além da matemática, foi tratada a identificação dos gêneros textuais; dessa forma, os estudantes puderam notar a diferença entre receita e outros gêneros. Questionados se sabiam identificar uma receita, uma estudante compartilhou sua resposta com a turma: "Dá para perceber porque a receita que a professora passou é menor e tem números e não vejo isso nos outros textos." Sendo assim, todos conheceram a estrutura de uma receita que contém: ingredientes, modo de preparo, como servir e para quantas pessoas rende. Posteriormente, comentou-se sobre os números fracionários que estavam presentes na receita. Alguns dos estudantes explicitaram que tais números representavam contas de divisão; já outros 
não souberam responder.

Xícara, colheres, pacote de farinha de trigo e recipientes adentraram a sala de aula. Esses materiais foram utilizados para introduzir de forma contextualizada os números fracionários presentes na receita. Então os estudantes leram a receita que estava no quadro, identificaram o número misto referente à medida a ser colocada, retirando-a com uma xícara diretamente do pacote de farinha de trigo e colocando no recipiente.

Como alguns estudantes não estavam compreendendo a parte fracionária do número, uma das crianças se predispôs a explicar. Ela foi à frente da sala, leu a receita na lousa e disse: "Essa receita diz para pôr 2 xícaras, você irá pegar a xícara e encher duas vezes e colocar na vasilha. Na frente do 2, tem outro número que é $1 / 2$, que é o mesmo número do chocolate. Você tem um chocolate com dois pedaços, não é? Se eu comer um pedaço quantos sobram?" O restante da turma respondeu que era 1. A seguir, ela disse: "Isso, mas como o chocolate inteiro era dois pedaços e comi um, sobra um, que ficou a metade! Sabemos que representa meio; então você vai colocar mais metade de uma xícara", mostrando para todos na classe com o trigo e a xícara (Figura 2).

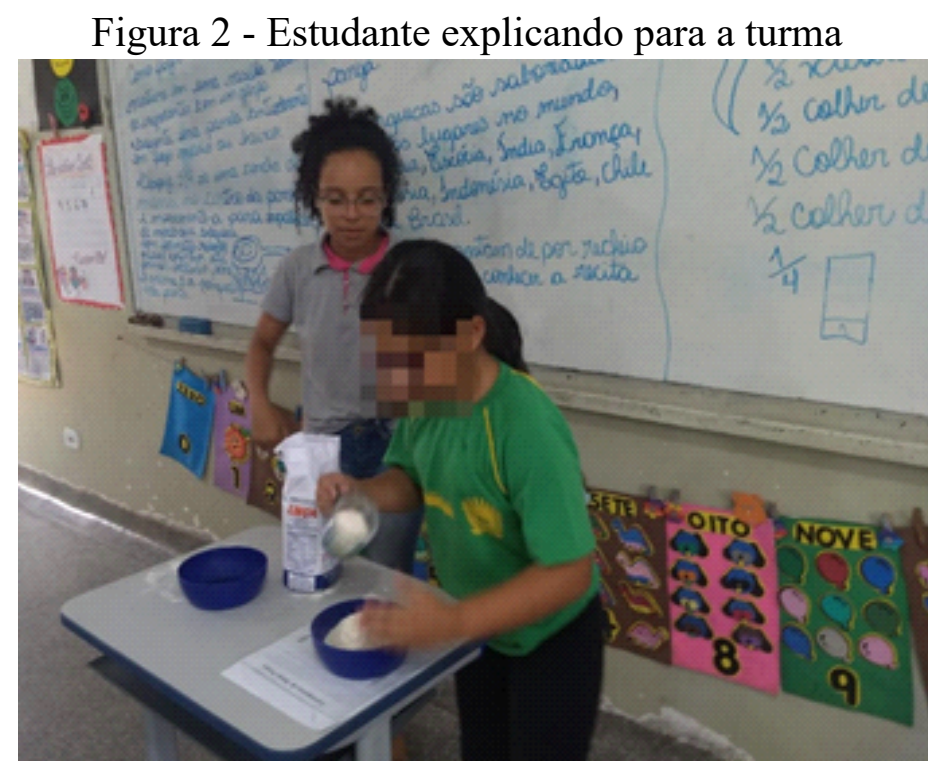

Fonte: arquivo das autoras.

Depois desta explicação, não restaram dúvidas. Em seguida, os estudantes revezaram para que participassem com medidas diferentes até que todos compreendessem. Assim a aula foi finalizada.

\section{Panquecas}


Neste dia, havia trinta estudantes e a aula foi iniciada perguntado se os estudantes lembravam da história lida na aula anterior e eles explicitaram oralmente algumas características do livro "As panquecas de Mama Panya". Entre elas, citaram o mercado, a forma como se vestiam, as árvores, os animais, a forma que falavam, a escola e a distância que percorriam para chegar até ela.

Então, questionou-se se lembravam o que a Mama Panya estava pretendendo cozinhar quando decidiu que iria ao mercado comprar ingredientes; todos responderam, com muito entusiasmo, que se tratava das panquecas. A seguir, a conversa foi sobre as panquecas ao redor do mundo, como cada cultura tinha seu jeito e adaptações para prepará-las: alguns costumam utilizar carne, presunto e muçarela; outros as fazem doce, com chocolate, com leite condensado, e até mesmo apenas a massa com pimenta, que era o caso da receita de Mama Panya. Em seguida, discutiu-se quem já havia comido panquecas e como foram preparadas. Todos se envolveram e contaram como as famílias costumavam preparar. "A minha coloca carne moída e comemos no almoço", exclamou um estudante. "A minha coloca queijo em cima e assa no forno!", afirmou outro, e alguns relataram que nunca provaram.

Assim, foi escrita, no quadro, uma receita de panquecas para prepará-la na sala. Foi organizado um espaço com uma mesa à frente da sala com todos os ingredientes para que se pudesse analisar as instruções e as medidas.

Foi dado início ao preparo pedindo que a turma lesse em voz alta a receita toda, para que, assim, pudessem acostumar-se com a estrutura de uma receita. Em seguida, vieram estudantes, de dois em dois, para fazerem a receita. Mas não foi tão simples assim; foi preciso entrar no clima de chefes de cozinha. Para tornar o momento característico de preparo de receitas, os estudantes colocaram toucas e aventais. Um deles brincou dizendo: "Agora viramos mini master chefs". A receita foi feita passo a passo: cada um ia à frente, colocava touca, avental e lia qual era o ingrediente que deveria acrescentar e sua medida, em voz alta para toda a turma, colocando-o no recipiente conforme Figura 3. 
Figura 3 - Estudante adicionando o leite.

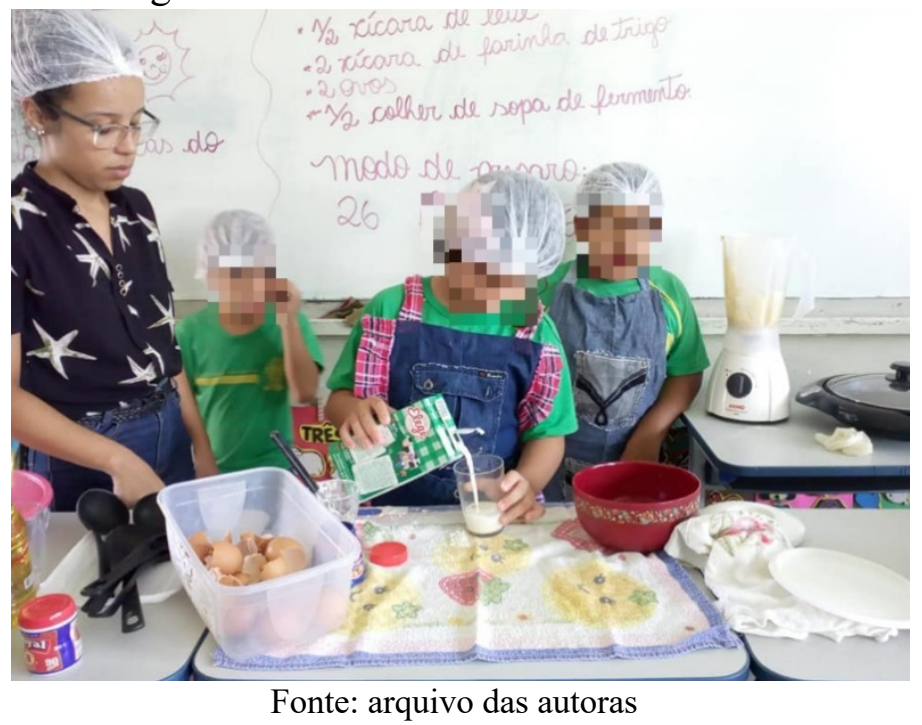

Após terminar de adicionar todos os ingredientes, o próximo da fila colocou a mistura em outro recipiente. Então, foi lida a receita analisando o que deveria ser feito na sequência. Os estudantes destacaram que a receita rende para 6 pessoas e que essa não era suficiente para todos. Eles calcularam quantas vezes seria necessário repeti-la para que os 30 comessem. Depois de dialogarem, essa questão foi resolvida em conjunto, no quadro.

A receita foi duplicada adicionando $6 \operatorname{com} 6$; e as anotações foram feitas pela professora no quadro e os estudantes disseram: "12". Então foi analisado: "Uma receita para doze pessoas já é o ideal?" E eles afirmaram que não; era necessário adicionar mais uma. Foi anotado no quadro: 12+6; alguns estudantes responderam "18!". Então questionou-se "Será que agora está bom? Todos serão servidos?", e afirmaram que não. Ainda era necessário adicionar mais; então, foi anotado: $18+6$, e responderam, após alguns minutos pensando: "24!" "E agora já está tudo certo?", questionou a professora. E responderam que não, pois alguns colegas ficariam sem comer; então mais uma adição foi registrada no quadro: 24+6. Essa não foi calculada mentalmente como as anteriores; para resolvê-la, os estudantes utilizaram o registro no caderno, e logo responderam que o resultado era 30 e que, agora sim, estava certo, que eram suficientes para todos os estudantes. Neste momento, um dos estudantes sugeriu que se fizesse mais uma receita para que as professoras também pudessem provar e, o que sobrasse, dividiriam entre todos. E, assim, foi feito.

Nesse processo, surgiu uma inquietação por parte dos estudantes: "Quantas vezes repetimos o número 6 em nossos cálculos?". Como estava exposto no quadro, foi mais fácil 
para chegarem a uma conclusão que logo foi expressa pelos estudantes em alto e bom som: "6 vezes". Foi perguntado se alguém sabia o que isso significava e uma estudante respondeu: "São o tanto de vezes que vamos repetir a receita."

Por fim, a receita foi realizada seis vezes dando a oportunidade para que todos pudessem ir à frente realizar uma parte dela. Depois, tudo foi colocado em um recipiente grande. A seguir, ficou acertado sobre o último passo, que se tratava de levar ao fogo, e que, por questão de segurança, essa etapa deveria ser realizada por um adulto. Neste caso, foi realizada pela primeira autora com auxílio da professora regente. Todos os estudantes receberam as panquecas que eles haviam feito e saborearam. Em seguida, professores e estudantes dialogaram sobre a importância da matemática para que a receita saísse perfeita e para que a panqueca ficasse saborosa.

\section{Borboletas}

$\mathrm{Na}$ terceira etapa de discussão sobre o livro "As panquecas de Mama Panya", estavam presentes 30 estudantes. Iniciou-se um diálogo sobre animais, diversidade e riqueza da fauna de cada país. Foi perguntado se eles se lembravam dos animais que haviam visto na história; todos responderam que sim e citaram alguns como girafa, zebra, tigre. Então, novamente foram questionados: "E da borboleta, alguém lembra?". Os estudantes começaram a responder ao mesmo tempo. Quando se acalmaram, ficou combinado que todos poderiam falar, um de cada vez. Então começaram a falar sobre as características da borboleta como grande e bonita de acordo com as palavras da classe. No decorrer da discussão, indagou-se sobre a principal característica da borboleta do Quênia.

Neste momento, a turma ficou em silêncio, então surgiu a necessidade de lembrar do momento em que a história relata características da borboleta. Alguns estudantes começaram a gritar: "Professora, a borboleta do Quênia é gigante". Então, buscou-se, no texto, qual era a medida da borboleta, e os estudantes identificaram que ela media $20 \mathrm{~cm}$ de uma asa a outra.

As crianças sentaram-se em duplas e cada uma recebeu dois pedaços de barbante, sendo um medindo $20 \mathrm{~cm}$ e outro, $7 \mathrm{~cm}$; foi pedido, primeiramente, que analisassem os barbantes e dissessem qual achavam que representava a borboleta do Quênia e qual representava a do Brasil; prontamente notaram a diferença e, para ter certeza, todos pegaram as réguas. Em duplas, mediram os barbantes para descobrir qual o tamanho exato de cada um deles. Foi observado que, para usar a régua, deveriam começar a contar do número "0" em diante e, assim, iniciaram (Figura 4). Após todos terminarem de medir, escolheram duas crianças para registrar 
a medida dos barbantes no quadro.

Figura 4 - Qual será a diferença entre o grande e o pequeno?

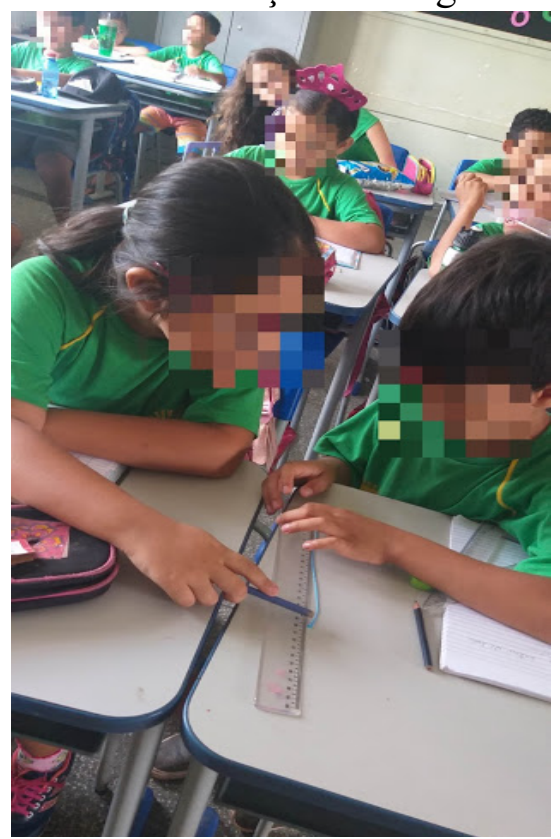

Fonte: arquivos das autoras

Por fim, traçaram uma reta de $20 \mathrm{~cm}$ no caderno com a régua e desenharam embaixo uma borboleta, seguindo a regra que consistia em iniciar uma asa em uma ponta da reta e a outra asa, na outra ponta. Os estudantes fizeram lindas borboletas do Quênia em seu caderno (Figura 5).

Figura 5 - A borboleta do Quênia

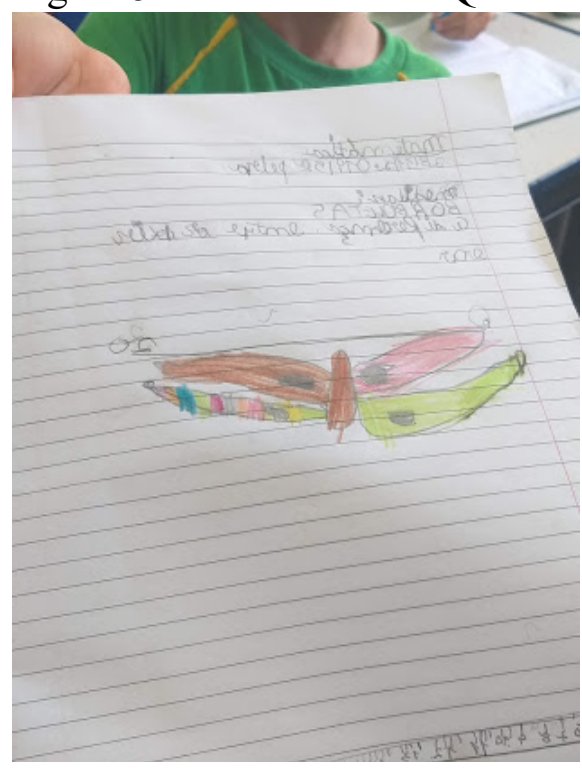

Fonte: arquivo das autoras

Com as asas coloridas de belas borboletas em uma página de papel, a aula foi finalizada. 


\section{Análise dos dados}

Os resultados deste estudo trazem indícios das potencialidades de se trabalhar a matemática contígua com a literatura infantil e questões étnico-raciais, nos anos iniciais do Ensino Fundamental. Tal conexão possibilita que os estudantes aprendam conhecimentos matemáticos como grandezas e medidas abordadas na pesquisa e, ao mesmo tempo, ampliem seus conhecimentos sobre aspectos étnicos-raciais.

Os estudantes ampliaram seus conhecimentos relacionados a grandezas e medidas de forma contextualizada. Entre eles, pode ser apontado o trabalho de medidas com números naturais, bem como uma introdução aos números fracionários por meio da receita presente em livro de literatura infantil. No contexto da história, tais números possuíam um referente, o que contribui para que as crianças os compreendessem e identificassem ao que cada um deles se referia. $\mathrm{O}$ preparo da receita na sala de aula permitiu que eles manuseassem os ingredientes e os recipientes, e refletissem sobre as medidas especificadas no texto instrucional e a relação à quantidade equivalente dos ingredientes que deveriam colocar.

Os estudantes também dialogaram sobre deslocamento e pontos de referência refletindo sobre o caminho que Adika e Mama Panya percorreram até a feira, assim como pela descrição do trajeto que cada estudante percorre da escola até sua casa. Os estudantes ampliaram seu vocabulário durante tal descrição e passaram a incorporar palavras como virar à direita, virar à esquerda, perto e longe, bem como selecionaram pontos de referências que podem ser utilizados em tal descrição. Ainda foi possível trabalhar com as crianças a forma correta de se medir com a régua começando exatamente do zero, não utilizando o espaço da régua que há antes dele, o que vai ao encontro das orientações do Pnaic (BRASIL, 2014). Tal atividade foi desenvolvida de forma contextualizada com a fauna do Quênia, representada por suas borboletas, o que favoreceu o engajamento das crianças. Neste momento, também foi trabalhado o conceito de diferença entre as medidas dos barbantes.

Quanto às questões étnico-raciais, foram enfatizados, dentre todos os aspectos, os personagens negros nas obras infantis, no processo de alfabetização matemática, que possuem um papel extremamente relevante para trazer perspectivas positivas sobre o povo negro para a sala de aula. De acordo com Munanga (2005), os discursos conduzidos que dizem sobre os negros ao longo da história, através de um olhar ocidental e etnocêntrico, apresentavam homens selvagens, pobres, inferiores e desprovidos de conhecimento, história e cultura. Assim, é essencial que o ensino de relações étnico-raciais deve estar presente desde o início da 
escolarização para mudança dessa visão estereotipada e fantasiosa. Faz-se necessário um compromisso dos educadores e das autoridades do campo educacional, cultural e político em apresentar e discutir outras abordagens a respeito da população negra. Para tanto, Munanga (2005, p. 16) sinaliza que

\footnotetext{
O resgate da memória coletiva e da história da comunidade negra não interessa apenas aos alunos de ascendência negra. Interessa também aos alunos de outras ascendências étnicas, principalmente branca, pois ao receber uma educação envenenada pelos preconceitos, eles também tiveram suas estruturas psíquicas afetadas.
}

Tendo em vista esta afirmação, quanto às aprendizagens propiciadas sobre questões étnico-raciais, foi possibilitado que os estudantes conhecessem um pouco do Quênia e aprendessem que este é um país do continente africano, proporcionando que reconhecessem um ponto de vista distante do olhar ocidental etnocêntrico e a importância da diversidade cultural. Os estudantes, ainda, utilizaram adjetivos positivos para se referir aos personagens, como, por exemplo, no momento em que observaram as roupas de Adika e Mama Panya e um estudante argumentou de forma espontânea e curiosa: "Nossa, como se vestem bem, as roupas são tão lindas e coloridas!"2. Ao notar essa interação dos estudantes com os personagens, enfatiza-se que "[...] as crianças merecem uma literatura que contemple a multiplicidade de histórias e vidas, reconhecendo as diversas identidades e valorizando aquelas que por muito tempo foram desconsideradas" (PEREIRA; DIAS, 2020, p. 193).

Foi possível que valorizassem, por meio desta imersão no Quênia, uma visita à África e suas riquezas sem precisar sair da sala de aula, pois Mary e Rich Chamberlin trouxeram um pedaço do país até eles. Os estudantes puderam criar significados para um livro de literatura infantil que traz em si a representatividade de personagens negros em um contexto positivo, o que contribui para o desenvolvimento de uma identidade cultural e social positiva (GUTSTEIN, 2006) das crianças.

\section{Considerações finais}

No decorrer deste artigo, foram enfatizadas potencialidades de realizar a junção da matemática, literatura infantil e questões étnico-raciais no processo de ensino e aprendizagem, mostrando que o estudante leitor tem grandes possibilidades de compreender os conhecimentos matemáticos quando estes são trabalhados de forma interdisciplinar, lúdica e contextualizada.

\footnotetext{
${ }^{2}$ Como observado na página 13 deste artigo.
} 
Entre os conceitos trabalhados, destacam-se: unidades de medidas que envolviam números naturais e fracionários, deslocamentos e noções espaciais, utilização da régua para medir e o conceito de diferença.

Desta forma, a análise dos dados permitiu considerar também o fato de que a educação se apresenta como uma importante ferramenta de combate ao racismo. A presença de personagens negros em histórias com contextos positivos contribui para a construção de uma identidade social e cultural, para o aprendizado e a representatividade da população negra, para a construção de uma sociedade democrática, humana e antirracista. Apresentar na literatura infantil uma variedade de corpos, sejam eles negros ou brancos, indígenas, masculinos, femininos, jovens, velhos, enfeitados, ensina aos leitores diferentes possibilidades de existência (FREITAS, 2014).

A conexão entre literatura infantil, matemática e questões étnico-raciais que valorizem a história e a cultura da população negra é importante para o processo de aprendizagem de todas as crianças, independentemente do seu pertencimento étnico-racial. Tal junção também possibilitou o ensino e a aprendizagem do respeito com a cultura do outro, da identificação da diversidade e sua valorização, proporcionado aos estudantes através da história "As panquecas de Mama Panya".

\section{Referências}

ADAM, Márcia Viviane dos Santos; JELINECK, Karin Ritter. Álgebra no ciclo de alfabetização: possibilidade de prática por meio da literatura infantil. In: XIII ENEM Encontro Nacional de Educação Matemática, 2019, Cuiabá/MT. Anais, Mato Grosso, 2019. Disponível em: $<$ https://www.sbemmatogrosso.com.br/ >. Acesso em: 20 jul. 2020.

BRASIL. Ministério da Educação (MEC). Pacto Nacional pela Alfabetização na Idade Certa: cadernos de formação, 2014. Disponível em:

$<$ https://wp.ufpel.edu.br/obeducpacto/category/pnaic-2014-cadernos-de-matematica/>. Acesso em: 28 out. 2020.

BRASIL. Presidência da República Casa Civil. Lei no 10.639, de 9 de janeiro de 2003. Disponível em: <http://www.planalto.gov.br/ccivil_03/Leis/2003/L10.639.htm>. Acesso em: 30 out. 2020.

CASTRO, Eliziane Rocha; NERES, Raimundo Luna; NASCIMENTO, Francisco Jeovane do; SOUSA, Gabriel Linhares de. Matemática e literatura: trabalhando conceitos matemáticos por meio de histórias, poemas e desafios. In: XIII ENEM - Encontro Nacional de Educação Matemática, 2019, Cuiabá/MT. Anais..., Mato Grosso, 2019. Disponível em: $<$ https://www.sbemmatogrosso.com.br/ >. Acesso em: 20 jul. 2020. 
CHAMBERLIN, Mary; CHAMBERLIN, Rich. As panquecas de Mama Panya. São Paulo: Edições Sm, 2005. 48 p. (Coleção Cantos do Mundo). Tradução Claudia Ribeiro Mesquita. Ilustrações Julia Cairns.

COELHO, Marciele Nazaré; CONSTANTINO, Francisca de Lima. Contributions of Brazilian Educational Policies: Possibilities of Dialogue and Appreciation of Ethnic and Racial Diversity in the School Context. IJRS - International Journal of Roma Studies v. 2, n. 1, March 2020 pp. 41-63. Roma. 2020. Disponível em:

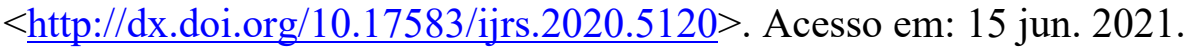

FREIRE, Paulo. Pedagogia da Indignação: cartas pedagógicas e outros escritos.

Organização e participação Ana Maria de Araújo Freire. São Paulo: Paz e Terra, 2014.

FREITAS, Daniela Amaral Silva. Literatura infantil dos kits de literatura afro-brasileira da PBH: Um currículo para ressignificação das relações étnico-raciais. 2014. 280 f. Tese (Doutorado) - Universidade Federal de Minas Gerais, Faculdade de Educação, Belo Horizonte, 2014. Disponível em: <daniela_amaral_silva_freitas_tese .pdf (ufmg.br) > . Acesso em: 25 nov. 2020.

GIL, Antônio Carlos. Métodos e técnicas de pesquisa social. 6. ed. São Paulo: Atlas, 2008.

GOLDENBERG, Mirian. A arte de pesquisar: como fazer pesquisa qualitativa em Ciências Sociais. Rio de Janeiro / São Paulo: Record, 2004. Disponível em: <https://

www.ufjf.br/labesc/files/2012/03/A-Arte-de-Pesquisar-MirianGoldenberg.pdf $>$. Acesso em: 28 out. 2020.

GUTSTEIN, Eric. Reading and writing the world with mathematics: toward a pedagogy for a social justice. New York: Routledge, 2006.

LANNES, Marina Badaró. O 'empoderamento crespo' na literatura infantil. 2019. 115f. Dissertação (Mestrado em Ensino) - Universidade Federal Fluminense, Santo Antônio de Pádua, 2019. Disponível em: <http://pdi.sites.uff.br/wp-content/ uploads/ sites/147/2019/09/DISSERTACAO-Marina-Badaro-Lannes.pdf $>$. Acesso em: 27 ago. 2020.

LINO, Trinidad Sanabria. Diccionario avañe'ẽ ilustrado. 7. ed. Buenos Aires: Ruy Díaz, 2008. 736p.

LOPES, Laurilene Cardoso da Silva; FILHO, Vicente Henrique de Oliveira. Literatura infantil como possibilidade de ampliação do conhecimento matemático: prática docente de uma professora alfabetizadora. In: XIII ENEM - Encontro Nacional de Educação Matemática, 2019, Cuiabá/MT. Anais, Mato Grosso, 2019. Disponível em: $<$ https://www.sbemmatogrosso.com.br/>. Acesso em: 20 jul. 2020.

MONTOITO, Rafael. Entrelugares: pequeno inventário inventado sobre matemática e literatura. Bolema [online], v. 33, n. 64, p. 892-915, 2019. Disponível em: < https:// www.scielo.br/scielo.php?script=sci_abstract\&pid=S0103-636X>. Acesso em: 26 out. 2020. 
MUNANGA, Kabengele (Org.) Superando o Racismo na Escola. Brasília: MEC, 2005.

PEREIRA, Sara da Silva; DIAS, Lucimar Rosa. Entre colos e afetos: a hora e a vez dos bebês na literatura infantil de temática da cultura africana e afro-brasileira. Revista da ABPN, v. 12, n. 33, p. 178-196, 2020. Disponível em:

$<$ https://abpnrevista.org.br/index.php/site/article/view/1008/873>. Acesso em: 25 nov. 2020.

PINHEIRO, Maiara Gabrieli; BEZERRA, Renata Camacho. Literatura e Matemática: a contação de história como ferramenta no processo de ensino da matemática. In: XIII ENEM Encontro Nacional de Educação Matemática, 2019, Cuiabá/MT. Anais, Mato Grosso, 2019. Disponível em: <https://www. sbemmatogrosso.com.br/ >. Acesso em: 20 jul. 2020.

REIS, Camila Maria dos; JULIO, Rejane Siqueira; EUFRÁSIO, Daniela Aparecida. Educação matemática e literatura infantil. . In: XIII ENEM - Encontro Nacional de Educação Matemática, 2019, Cuiabá/MT. Anais..., Mato Grosso, 2019. Disponível em: $<$ https://www.sbemmatogrosso.com.br/ >. Acesso em: 20 jul. 2020.

SANTOS, Francieli Aparecida Prates dos; CIRÍACO, Klinger Teodoro. Possibilidades de trabalho com matemática e literatura infantil no ciclo da alfabetização a partir do acervo do PNAIC. In: XIII ENEM - Encontro Nacional de Educação Matemática, 2019, Cuiabá/MT. Anais, Mato Grosso, 2019. Disponível em: $<$ https://www. sbemmatogrosso. com.br/ >. Acesso em: 20 jul. 2020.

SILVA, Izabela Cristina Bezerra da; ANDRADE, Amanda Regina dos Santos; GUIMARÃES, Gilda Lisbôa. Literatura infantil e aprendizagem de estatística. In: XIII ENEM - Encontro Nacional de Educação Matemática, 2019, Cuiabá/MT. Anais..., Mato Grosso, 2019. Disponível em: <https://www.sbemmatogrosso.com.br/>. Acesso em: 20 jul. 2020 .

SOUZA, Ana Paula Gestoso; CARNEIRO, Reginaldo Fernando. Um ensaio teórico sobre literatura infantil e matemática: práticas de sala de aula. Educ. Matem. Pesq., São Paulo, v. 17, n. 2, p. 392-418, 2015. Disponível em: < https://revistas. pucsp.br/ emp/article/viewFile/17171/pdf>. Acesso em: 20 set. 2020.

SOUZA, Marinalva Conceição de; CÔCO, Dilza. Formação de professores de anos iniciais: interfaces entre literatura infantil e grandezas e medidas. In: XII ENEM- Encontro Nacional de Educação Matemática, 2016, São Paulo - SP. Anais, São Paulo, 2016. Disponível em: $<$ http://www.sbembrasil.org.br/enem2016/anais/autores-B.html > . Acesso em: 20 ago. 2020.

WEISSHEIMER, Raquel Fensterseifer; CUNHA, Aline Vieira da; MONTOITO, Rafael. O desenvolvimento das relações topológicas na construção do espaço pela criança: a literatura como uma via de acesso. In: XIII ENEM - Encontro Nacional de Educação Matemática, 2019, Cuiabá/MT. Anais..., Mato Grosso, 2019. Disponível em:

$<$ https://www.sbemmatogrosso.com.br/>. Acesso em: 20 jul. 2020. 